\title{
BMJ Open Comparison between primary care service delivery in Malaysia and other participating countries of the QUALICOPC project: a cross- sectional study
}

\author{
Ming Tsuey Lim (D) , ${ }^{1}$ Su Miin Ong (D) , ${ }^{1}$ Seng Fah Tong (D) , \\ Peter Groenewegen (D) , , Sheamini Sivasampu (D) ${ }^{1}$
}

To cite: Lim MT, Ong SM, Tong SF, et al. Comparison between primary care service delivery in Malaysia and other participating countries of the QUALICOPC project: a crosssectional study. BMJ Open 2021;11:e047126. doi:10.1136/ bmjopen-2020-047126

- Prepublication history and additional online supplemental material for this paper are available online. To view these files, please visit the journal online (http://dx.doi.org/10. 1136/bmjopen-2020-047126)

MTL and SMO contributed equally.

Received 19 November 2020 Revised 16 March 2021 Accepted 19 April 2021
Check for updates

(c) Author(s) (or their employer(s)) 2021. Re-use permitted under CC BY-NC. No commercial re-use. See rights and permissions. Published by BMJ.

For numbered affiliations see end of article.

Correspondence to

Mr Su Miin Ong;

ongsm@crc.gov.my

\section{ABSTRACT}

Objectives Most countries including Malaysia have set goals to incorporate a strong primary care into the healthcare system. The aim of this study was to evaluate the strength of service delivery process dimensions in Malaysia and compare it with England, the Netherlands, Spain, North Macedonia, Romania and Turkey which participated in the Quality and Costs of Primary Care (QUALICOPC) study.

Methods This cross-sectional study utilised the QUALICOPC study data on primary care performance, which was conducted in 2011-2013 (QUALICOPC in Europe Australia, New Zealand and Canada) and 2015-2016 (Malaysia). A standardised questionnaire was completed by primary care practitioners from participating countries. Multilevel regression analysis and composite scores were constructed to compare the performance of primary care on four process dimensions: accessibility, comprehensiveness, continuity of care and coordination. Results The high-income countries with strong primary care performed better in comprehensiveness, continuity and coordination but poorer in accessibility to services compared with upper-middle-income countries. Among the upper-middle-income countries, Malaysia scored the best in comprehensiveness and coordination. None of the studied countries were having consistent performance over all indicators either in their respective best or worst primary care services delivery dimensions.

Conclusions There is a wide variation in primary care services delivery across and within the studied countries. The findings indicate room for quality improvement activities to strengthen primary healthcare services. This includes addressing current healthcare challenges in response to the population health needs which are essential for more integrated and efficient primary care services delivery.

\section{INTRODUCTION}

Primary care essentially encompasses the provision of an integrated healthcare service by physicians and other healthcare professionals which addresses an individual's health
Strengths and limitations of this study

- This study used a standardised questionnaire to compare primary care service delivery between upper-middle-income countries and countries with reported strong primary care services.

- For the first time in these countries, this study enables the identification of strengths and weaknesses in the primary care dimensions relative to each country.

- The self-reporting by primary care practitioners may be biased by social desirability and may not reflect true patients' experience.

within the family and community context. ${ }^{12}$ It is generally a patient's first point of contact with the healthcare system. The benefits of a good primary care system include better overall population health, reduced socioeconomic disparities in health, and avoidance of unnecessary hospitalisations. ${ }^{3}$ Studies have shown that strong primary care has the potential in coping with the current challenges of healthcare systems, including ageing population, health inequities, high prevalence of chronic diseases, technology changes as well as rising healthcare expenditures. ${ }^{3-5}$ Strong primary care is characterised by its ease of accessibility to services and ability to deliver comprehensive, coordinated and continuous care. ${ }^{14-7}$ Recent evidence demonstrates that countries with healthcare systems which centres on quality primary care are poised to achieve almost all the Sustainable Development Goals compared with those with a hospital-focused system or a low investment in healthcare. ${ }^{89}$

Ever since the Alma-Ata declaration in 1978, ${ }^{10}$ most countries including Malaysia, have set goals to incorporate a strong primary 
care into the healthcare system. Primary care services in Malaysia are provided both by the public and private sector which are separated in their organisation, financing and governance. The public sector is tax funded, while the private sector is funded through fees for services, private health insurance and by employers as part of employee health benefits. ${ }^{11}$ All the public clinics are collaborative practices staffed with a skillmix of primary care providers such as doctors, certified nurses, pharmacists, assistant medical officers, physiotherapists, nutritionists and occupational therapists. ${ }^{11}$ The private clinics on the other hand are privately owned practices. A majority of them are single practitioner practices. ${ }^{11}$ Their workforce comprised primarily of doctors and non-certified nursing aides. ${ }^{12}$ The private clinics are mainly concentrated in the urban and suburban areas while the public clinics have a wider coverage in both urban and rural areas. Nevertheless, there are six times more private clinics compared with public clinics, but the public clinics are seeing more than three times the patients load compared to private clinics. $^{12}$

Despite the recognition of the importance of primary care to healthcare, little is known about the current strength of the Malaysian primary care system. Further, there is lack of comparison of the performance of primary care services between low-income and middleincome countries and high-income countries (HICs) with a strong primary care system. The differences in the provision of primary care in terms of organisation, source of finances and governance ${ }^{13} 14$ may affect the primary care service delivery, hence a benchmarking exercise is important to evaluate the strengths and weaknesses of primary care services.

With the participation of Malaysia in the Quality and Costs of Primary Care (QUALICOPC) study in 2015-2016 and the first in Asia, ${ }^{1516}$ we had the opportunity to benchmark the strength of Malaysian primary care services against other countries that participated in the QUALICOPC study. QUALICOPC is an international study that evaluates the performance of the primary care system in 34 countries in terms of quality, equity and cost. ${ }^{17} 18$ Moreover, QUALICOPC was designed for benchmarking performance and to facilitate primary care reform through international comparison. ${ }^{17} 18$

Therefore, the objectives of this study are to evaluate the Malaysian primary care service delivery performance in the dimensions of accessibility, comprehensiveness, continuity of care and coordination, and to compare it with selected participating countries of the QUALICOPC study, namely England, the Netherlands, Spain (as examples of HICs with strong primary care), North Macedonia, Romania and Turkey (as examples of upper-middleincome countries (UMICs)). ${ }^{19} 20$

\section{METHODS}

\section{Data source}

This cross-sectional study used the data collected from the study on QUALICOPC in Europe and from a comparable project in Malaysia to compare the different dimension in primary care service delivery. QUALICOPC is a comparative cross-sectional survey that was conducted in Europe, Australia, New Zealand and Canada, and in Malaysia. The survey consists of four sets of questionnaires that were designed to collect information about the primary care settings, primary care practitioners (services provided) and patients (experiences and values). Details about the study protocol have been described and published elsewhere. ${ }^{1718}$

\section{QUALICOPC in Europe, Australia, New Zealand and Canada}

QUALICOPC was conducted in 31 European countries and three non-European countries. In each country, a nationally representative sample of primary care practitioners and patients was selected to participate in the study. Data collection took place between October 2011 and December 2013. The sampling response rates and characteristics were described in detail by Groenewegen et. al. ${ }^{21}$

\section{QUALICOPC in Malaysia}

In Malaysia, the data were collected in two phases involving two sectors. The data for the public sector were collected in 2015 and subsequently for the private sector in 2016. The data from both sectors were used in combination to represent Malaysia's overall primary care performance in the respective dimension. The samples collected were representative of each sector. Out of the 222 practitioners in public clinics sampled, 221 responded (response rate of $99.5 \%$ ), while for the private sectors, 510 clinics were approached and 239 responded (response rate of 46.9\%). The details of the conduct of the study were described elsewhere. ${ }^{15} 16$ To represent Malaysia in this study, the samples were weighted according to the distribution of clinics by each sector as reported in the National Medical Care Statistics $2014 .^{11}$

\section{Study context}

The data used in this study were from the practitioner's questionnaires, which included primary care settings and service provisions. Six countries from the European QUALICOPC were chosen for this comparison. Among the HICs as defined by the World Bank, ${ }^{20}$ England, the Netherlands and Spain were chosen due to the reported strength in their primary care system. ${ }^{19}$ While, Turkey, North Macedonia and Romania were chosen because together with Malaysia, they were classified as UMICs by the World Bank. ${ }^{20}$

\section{Questionnaires}

The practitioner's questionnaires were designed to collect information about different dimensions in primary care. ${ }^{17}$ We mapped a total of 34 questions/indicators from QUALICOPC to the dimensions of accessibility, 
comprehensiveness, continuity and coordination of care according to the WHO definition of characteristics of primary care. ${ }^{7}$ The details of the indicators and their corresponding dimensions were shown in online supplemental table 1 .

\section{Analysis}

Each indicator scale for each country was derived from multiple items from the questionnaires. This was constructed through multilevel analysis using ecometric approach. ${ }^{22}$ The items in each indicator were the lowest level of the model nested within individual practitioners which in turn were nested within each country. Using the random intercept model, the value of intercept for each indicator was the overall average of that indicator, and the residuals were used to compute the average value of that indicator for each country. This will allow us to compare the performance of each country and rank them for a particular indicator.

As each indicator was measured in different scales (online supplemental table 1), a standardised z-score was calculated for each indicator of each country by using the overall average. A positive z-score indicated the country performed above average in that particular indicator, while a negative score showed that its performance was below average. By using z-score, all indicators within a dimension will be rescaled into a common scale. Therefore, a composite score for each dimension of each country can be created by summing z-scores of the indicators under each dimension. Finally, the performance of each country was compared using the composite score of each dimension.

All analysis was done using R V.3.6 and the multilevel analysis was done using the module lme 4 in R.

\section{Patient and public involvement}

There were no patients or public involvement in the design, conduct, reporting and in the dissemination plans of this research.

\section{RESULTS \\ Demographics}

There were 1959 primary care practitioners who responded to the survey from the seven countries. The median age was 48 years old with IQR of 40-55. Malaysia was the country with the youngest median (37, IQR 29-51.25) while the Netherlands was the oldest (54, IQR 48-59). Majority of the respondents were female (51.7\%) but the composition by gender varies across different countries. In England, the Netherlands, Turkey and Malaysia, the respondents were majority male, while in the other countries they were predominantly female. In terms of practice location, more than a third of the respondents were practising in a city, followed by town (21.4\%), mixed urban-rural area (14.6\%), suburban area (13.1\%) and rural area (12.8\%). Respondents from Spain, Turkey and North Macedonia mainly had their practices in the city, while England, the Netherlands and Malaysia were in town. Romanian practitioners were mainly from the rural region. The details of the demographics were shown in online supplemental table 2.

\section{Overall rank}

Figure 1 shows the performance of the countries on each of the four dimensions and their respective composite z-score. England had the strongest primary care service delivery, as it performed the best in three out of the four dimensions. Interestingly, the UMICs had better accessibility to primary care compared with the HICs. Among the UMICs, Malaysia ranked the best in three out of the four dimensions, except for accessibility.

\section{Accessibility}

From the composite z-score in figure 1A, Romania showed the highest score (3.67) in the accessibility dimension. This was followed by Malaysia and North Macedonia with the score of 1.56 and 1.40 respectively. England (-4.14) and the Netherlands $(-3.70)$ were the countries with the lowest score in this dimension.

Looking at individual indicators (figure 2), the Netherlands was the best in providing out of office hours primary care services (figure 2: 31. Service after hours and 32. Service weekend), but not by the usual practices as indicated by the low score in the after hours indicator. Healthcare centres in Turkey were in closer proximity with each other compared with other countries. Romania provided the most financial aid while Spain saw the least defaulters due to financial constraint. Malaysia was the best in providing walk-in hours and it was also the country that did not impose any restrictions in accepting new patients.

\section{Comprehensiveness}

The three countries with strong primary care system occupied the top three positions in this dimension as shown in figure 1B. The highest total score was 7.76 obtained by England while all the UMICs were below average in providing comprehensive care.

Out of the 11 indicators in figure 3, England was the top performer in five of them, and was placed second in another three of them. Primary care practices in the Netherlands performed significantly more minor procedures compared with other countries. Malaysia on the other hand, showed to have the most comprehensive access to medical equipment and X-ray services.

\section{Continuity}

In the case of continuity (figure 1C), England remained on the top in this dimension with a total score of 4.42, followed by the Netherlands (2.91), Malaysia (1.49) and Romania (1.23). In comparison, Spain, Turkey and North Macedonia all scored in the negative region for this dimension.

England was performing significantly above the population average for all the indicators, with the exception of factors considered during referral which Romania 


\section{(A) Accessibility}

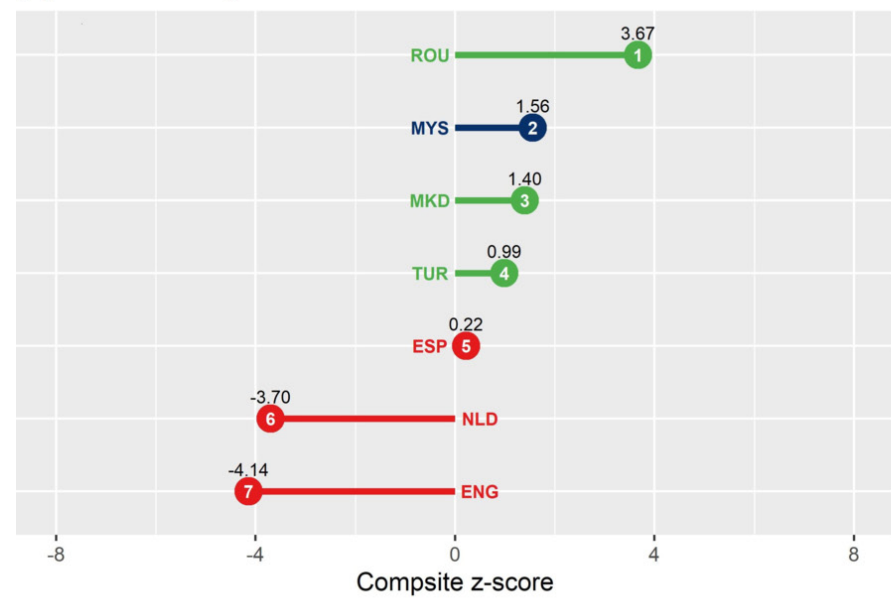

(c) Continuity

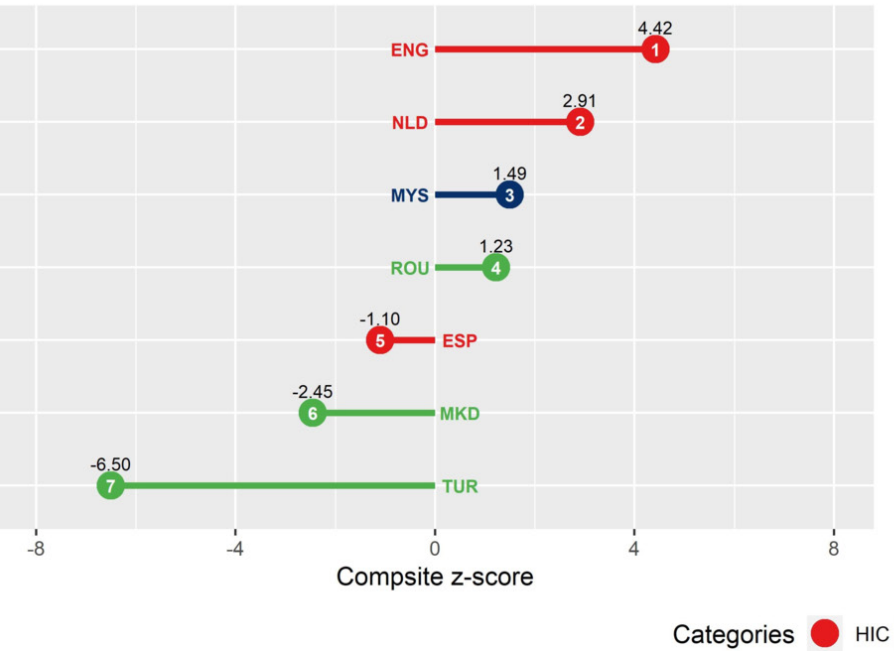

(в) Comprehensiveness

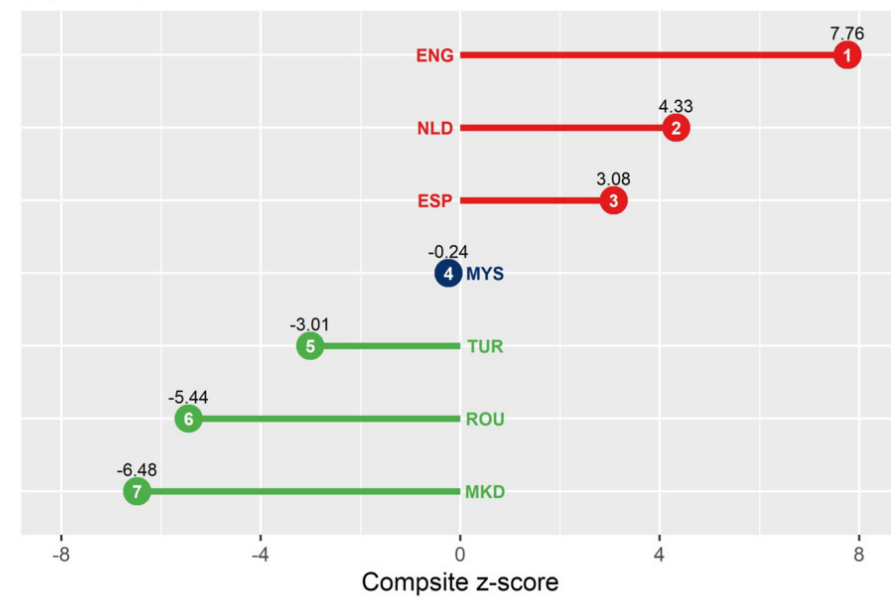

(D) Coordination

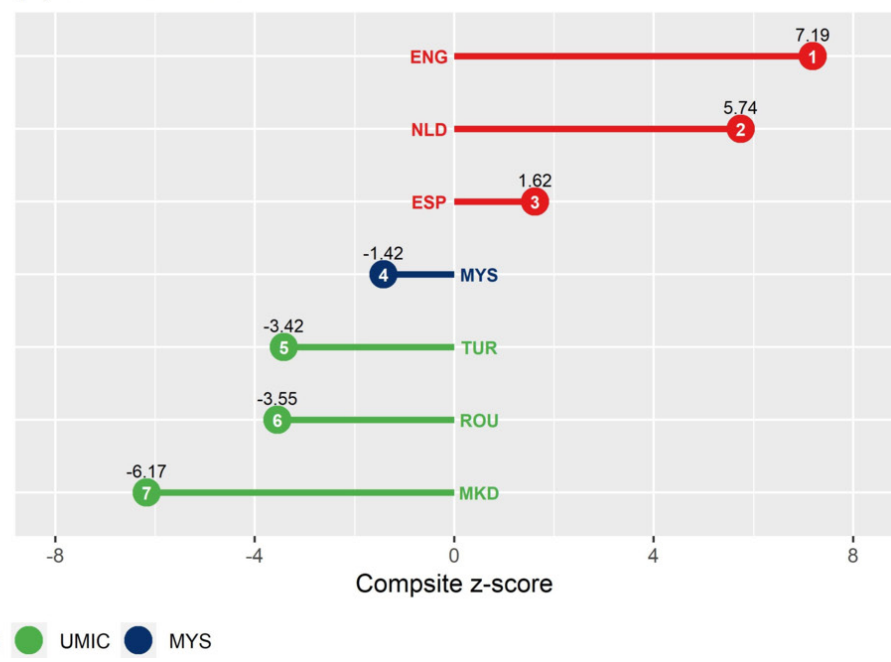

Figure 1 Ranking of each country in the four dimensions. The rank was based in the composite z-score of each country in the respective dimension. The high-income countries (HICs) in this comparison were England (ENG), the Netherland (NLD) and Spain (ESP). While the upper-middle-income countries (UMICs) consist of Malaysia (MYS), North Macedonia (MKD), Romania (ROU) and Turkey (TUR).

performed the best at as depicted in figure 4 . The Netherlands scored the best at three indicators, they were shared decision making, ensuring informational continuity and regular medical record keeping. England was the best in keeping comprehensive medical records, while Spain ranked the best at receipt of discharge summary, respectively.

\section{Coordination}

From figure 1D, the top three performers in this dimension were once again, England (7.19), the Netherlands (5.74) and Spain (1.62). North Macedonia was the worst performing country followed by Romania and Turkey.

England scored the highest in three out of the eight indicators (figure 5). The primary care doctors in the Netherlands were exceptionally frequent in seeking advice from medical specialist. Although Spain was the top performer in terms of group practice and having a good mixture of professions in the practice, they were relatively weak in collaborating with other professions and involvement in disease management programme. Surprisingly, Malaysia had the highest score in the use of referral letter.

\section{DISCUSSION}

\section{Summary of main findings}

To our knowledge, this is the first study to compare the strength of primary care service delivery in Malaysia against other UMICs and countries with reported strong primary care services, using the same indicator set identified for primary care dimensions in QUALICOPC study. ${ }^{17} 18$ In this paper, the ranking, based on the dimension total score, is used as proxy to indicate the strength of primary care service delivery in the respective dimension.

Our study showed that the primary care services delivery as reported by the practitioners vary considerably among the studied countries. The source of variation between the countries may lie in the features of the healthcare system in terms of organisation structure, workforce development as well as healthcare financing 


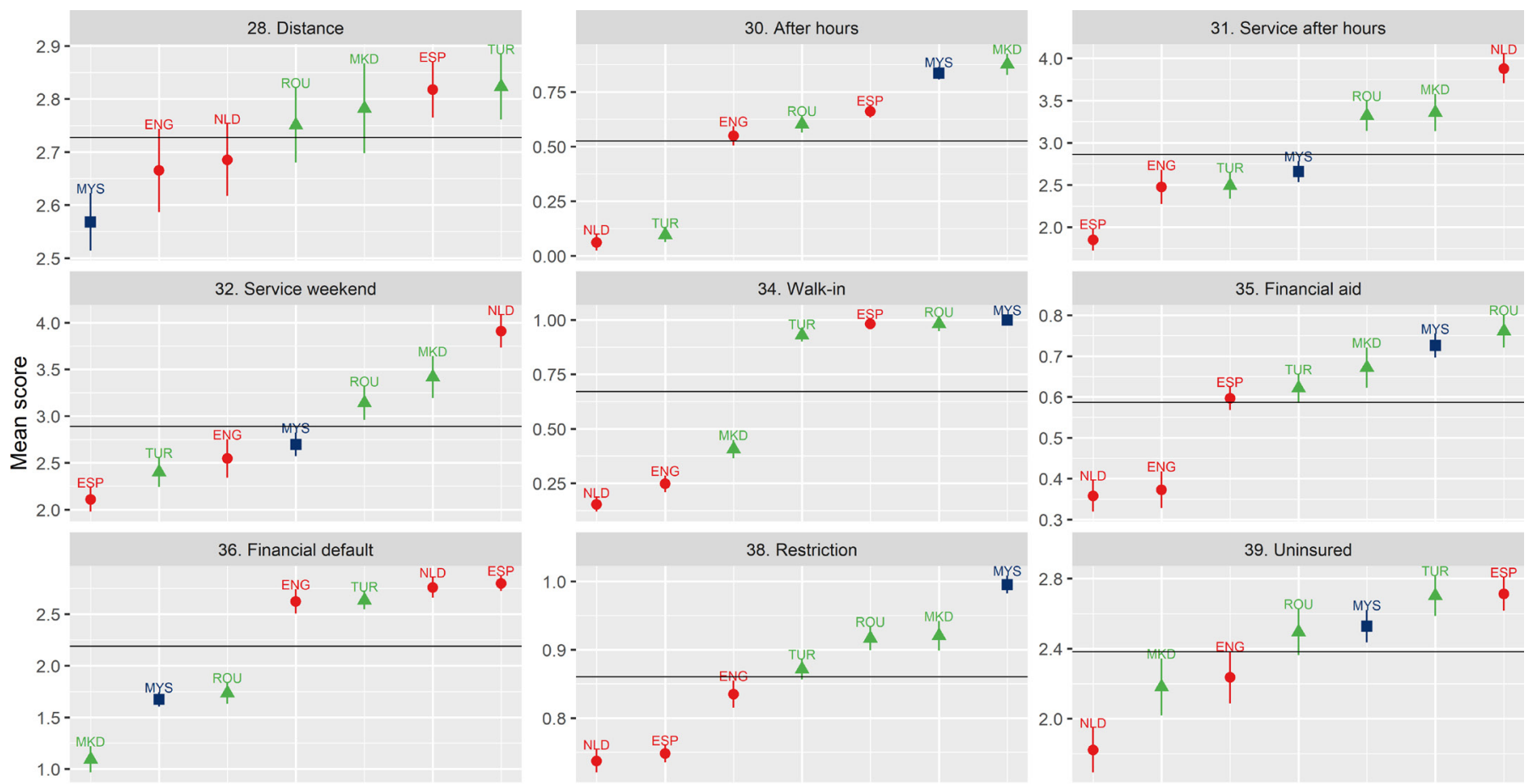

Categories - HIC $\approx$ UMIC $*$ MYS

Figure 2 Countries' scores for nine indicators that measure the dimension of accessibility. The horizontal line indicates the population average of each indicator, and the error bars indicate the $95 \% \mathrm{Cl}$ of the countries' estimates. The high-income countries (HICs) in this comparison were England (ENG), the Netherland (NLD) and Spain (ESP). While the upper-middle-income countries (UMICs) consist of Malaysia (MYS), North Macedonia (MKD), Romania (ROU) and Turkey (TUR).

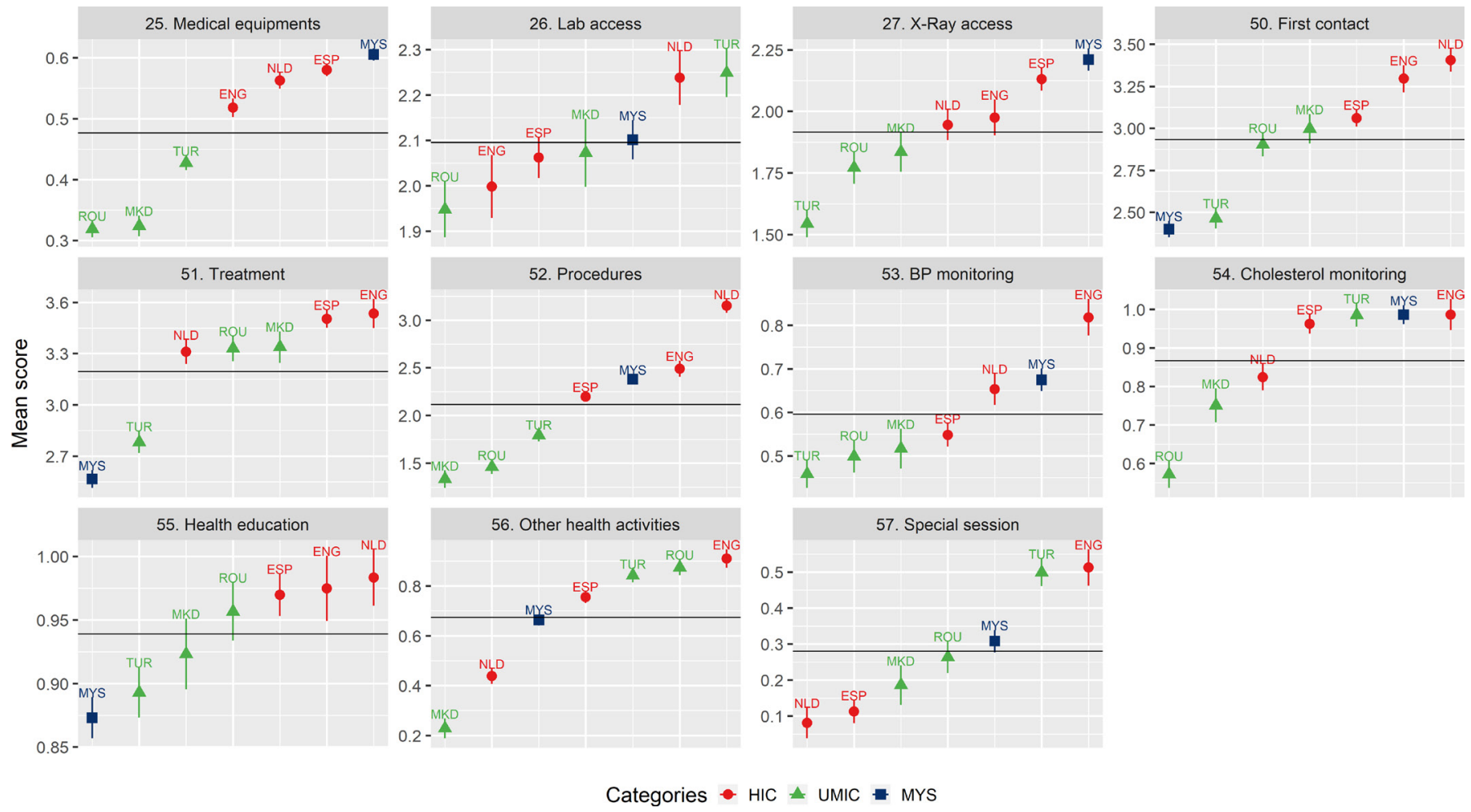

Figure 3 Countries' scores for 11 indicators that measure the dimension of comprehensiveness. The horizontal line indicates the population average of each indicator, and the error bars indicate the $95 \% \mathrm{Cl}$ of the countries' estimates. The high-income countries (HICs) in this comparison were England (ENG), the Netherland (NLD) and Spain (ESP). While the upper-middle-income countries (UMICs) consist of Malaysia (MYS), North Macedonia (MKD), Romania (ROU) and Turkey (TUR). 


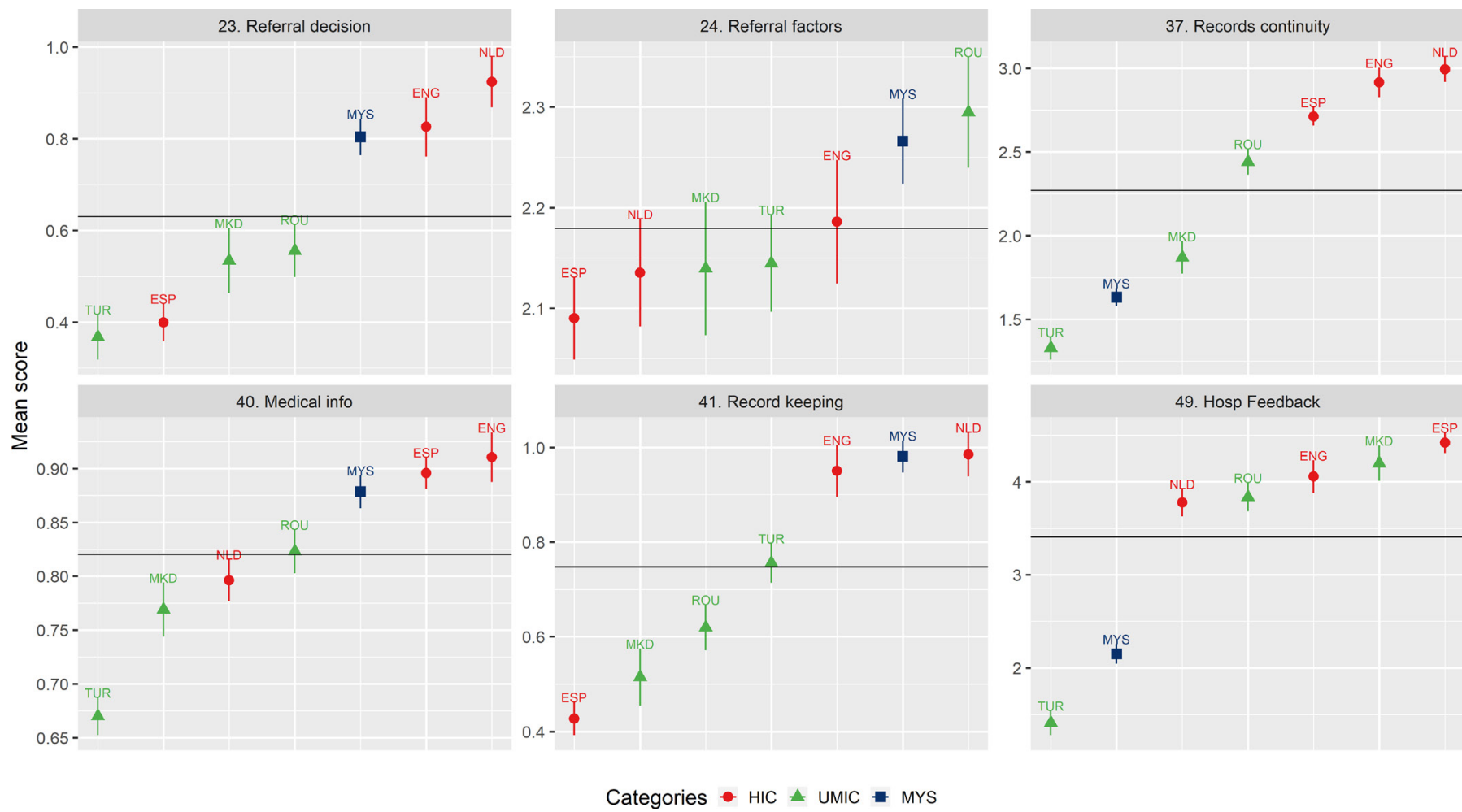

Figure 4 Countries' scores for six indicators that measure the dimension of continuity. The horizontal line indicates the population average of each indicator, and the error bars indicate the $95 \% \mathrm{Cl}$ of the countries' estimates. The high-income countries (HICs) in this comparison were England (ENG), the Netherland (NLD) and Spain (ESP). while the upper-middle-income countries (UMICs) consist of Malaysia (MYS), North Macedonia (MKD), Romania (ROU) and Turkey (TUR).
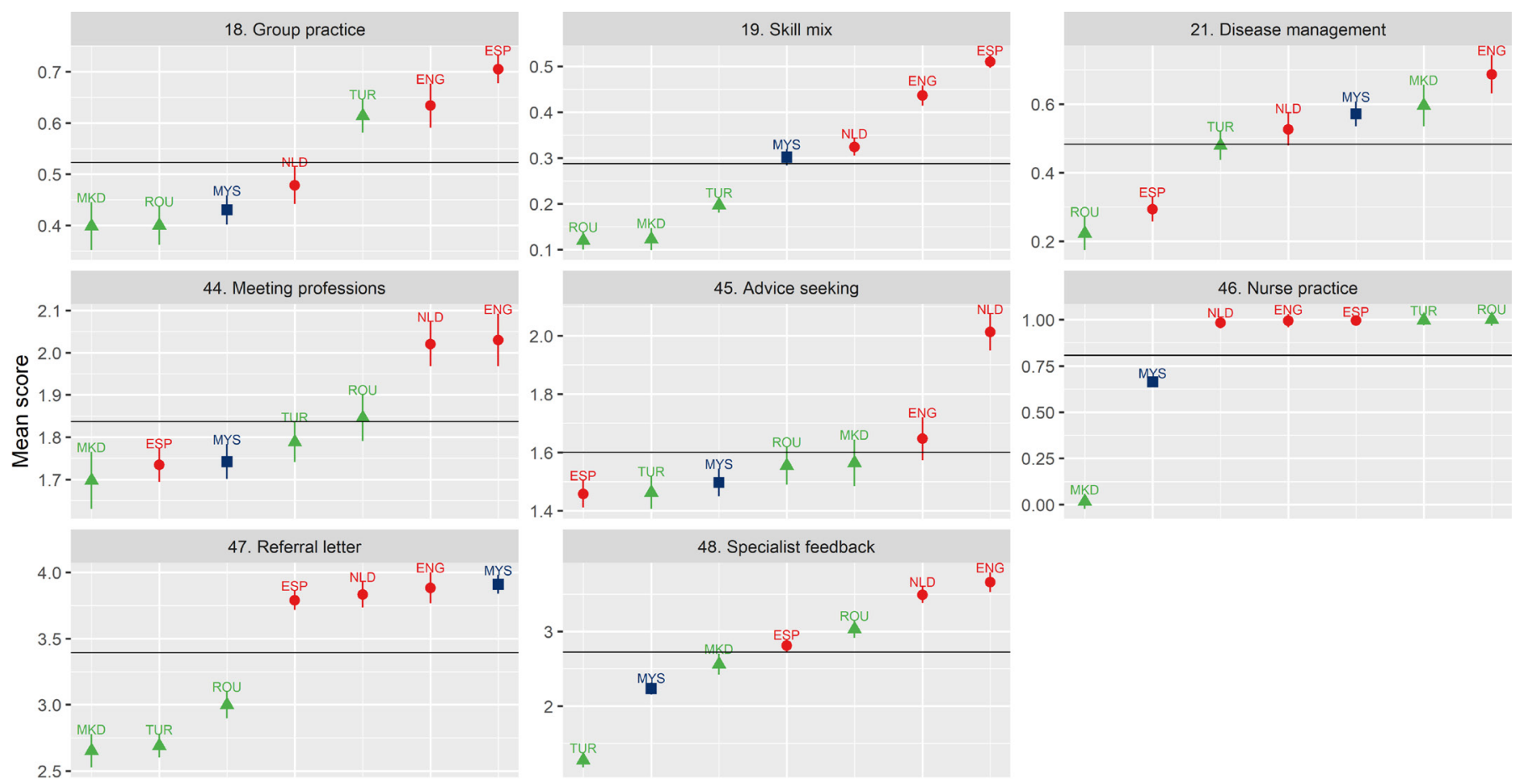
$0.4-$
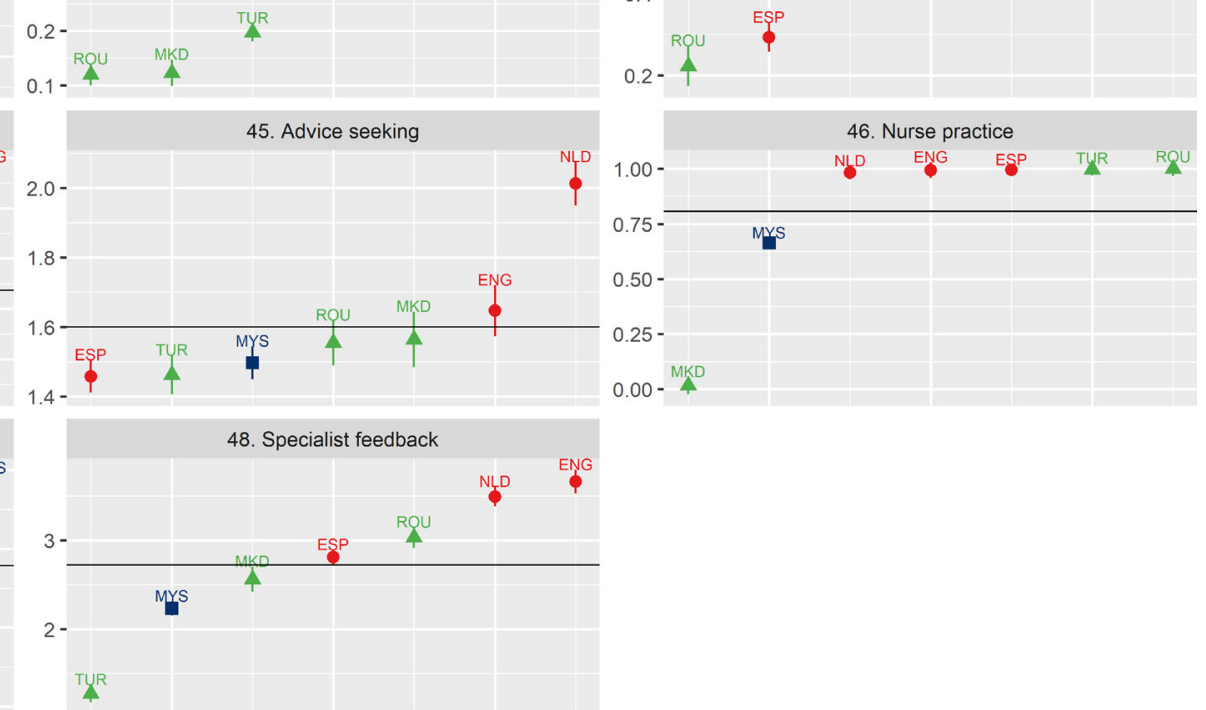

Categories - HIC $\approx$ UMIC $=\mathrm{MYS}$

Figure 5 Countries' scores for eight indicators that measure the dimension of coordination. The horizontal line indicates the population average of each indicator, and the error bars indicate the $95 \% \mathrm{Cl}$ of the countries' estimates. The high-income countries (HICs) in this comparison were England (ENG), the Netherland (NLD) and Spain (ESP). While the upper-middle income countries (UMICs) consist of Malaysia (MYS), North Macedonia (MKD), Romania (ROU) and turkey (TUR). 
and expenditure, provision of services, and primary care policies and regulations. ${ }^{523}$ Some of key organisational features of the countries are shown in (online supplemental table 3).

Overall, England had the strongest primary care service delivery with best performance in comprehensiveness, continuity and coordination. This was not surprising, as studies had shown that primary care system with gatekeeping and primarily group practices are better in providing comprehensive, continued and coordinated care, ${ }^{24}$ which are characteristic of the English primary care system (online supplemental table 3). However, the chosen countries with strong primary care had poorer accessibility to primary care services compared with the UMICs.

\section{Accessibility}

Accessibility is an important feature of primary care and primary care should be within reach to all, regardless of race, gender, culture, religion, political belief, socioeconomic condition or any category of complaint or health-related problem. ${ }^{7}$ In this study, we observed that accessibility of services varied across and within the studied countries. Generally, UMICs fared better in overall accessibility than the HICs.

Gaps in access to primary care services may occur due to a number of reasons, such as limited office hours, ${ }^{25}$ remoteness from health services, ${ }^{26}$ lack of health insurance coverage $e^{27}$ or insufficient supply of primary care providers. ${ }^{26}$ The possible explanation for better performance by the UMICs in this dimension is that the UMICs are primarily focusing in improving access and uptake of primary care services. In comparison, the main development aim for the HICs is to improve quality and patient experience, and to reduce reliance on hospital care. ${ }^{28}$ Nevertheless, the Netherlands was the top country in providing out-off office hours and weekend services. The reason for the high out-off office hours services could be attributed to the implementation of after-hours care system in which the general practitioner (GP) cooperatives are run by GPs on rotation basis to reduce the demand of emergency care needs. ${ }^{29}$ Care received outside office hours or on weekends which is also part of continuity of primary care is associated with improved patient outcomes and lower emergency department (ED) visit. ${ }^{31}$ Moreover, ED visits cost more than primary care visits. $^{3233}$

\section{Comprehensiveness}

Comprehensiveness is measured by the broadness and scope of services offered to address the healthcare needs of patients. ${ }^{12434}$ The performance in this dimension is also related to the availability of medical equipment as well as the availability of supporting staff to handle the equipment in primary care practices. ${ }^{35}$

The results of this study showed that the three countries with strong primary care have a better overall performance in comprehensiveness than the UMICs. These were mainly attributed to the involvement in treatment and follow-up of acute and chronic conditions, minor technical procedures and preventive treatments areas in the primary care provision of services. The possible explanation maybe due to the gate-keeping system and expansion of primary care services implemented in these countries, which shifted the responsibilities of minor procedures, diagnosis and management of certain illnesses to primary care. $^{36}$

\section{Continuity}

Continuity of care refers to how the healthcare of an individual is connected over time. ${ }^{37}$ It comprised interrelated aspects including management, informational and relational continuity. ${ }^{37}$ In this analysis, England was still ranked the top followed by the Netherlands, Romania, Malaysia, Spain, North Macedonia and Turkey. England was consistently placed in the top three in all of the indicators measuring continuity.

In primary care, medical record keeping forms the basis on which informational continuity of care is established. The information can be stored in paper records or electronically. However, the use of electronic medical records is more advantageous as it allows a quick flow of information across providers in decision making, efficient and effective organisation of referrals and efficient communication between GPs and patients and generally enhances continuity. Hence it is not surprising to see countries that invested heavily in effective information technology (IT) usage like England and the Netherlands ranked higher in indicators measuring informational continuity. ${ }^{38}$

\section{Coordination}

Coordination of care involves managing and integrating care between providers across all levels of care and time in order to achieve safer and more effective care. ${ }^{49} 40$ The main goal of care coordination is to meet patient's needs and preferences in high-quality healthcare delivery. Once again, this dimension was topped by England, the Netherlands and Spain, with Malaysia scoring the highest among UMICs.

There are many factors that can affect coordination of care. An effective referral system within a country across different care levels is crucial in improving care coordination. Especially with the increase use of IT services as mentioned above, quick flow of information across providers can be achieved and allow for effective organisation of referral. In addition, expansion of the roles of support staff, and establishment of disease management programme and multidisciplinary team within the practice are some of the steps taken by England and the Netherlands to improve coordination of care in primary care. $^{3841}$

\section{Policy implications for Malaysia}

From this study, we have shown that Malaysia has an overall better performing primary care compared to other UMICs. Nevertheless, there are several aspects which can 
be identified to strengthen the existing primary care system.

First, for accessibility, there may be a need to extend after-hours services and reduce physical distances between healthcare providers. Second, comprehensiveness could be improved with expanding spectrum of services to include ambulatory care sensitive conditions. Policies on task-shifting from hospital to primary care should also be made clear, in conjunction with public awareness campaign to educate the patients. Finally, for continuity and coordination, efforts should focus on ensuring not only effective cross-level communication but also within primary care practices itself. An effective approach is through establishing an electronic health record system which spans across primary, secondary and tertiary healthcare systems.

As for future research, given that the primary care services in Malaysia exist in two parallel system, there is a need to identify and compare the strengths and weaknesses of service delivery process between the two sectors. This will provide opportunities for the public-private partnership by complementing each other to strengthen the overall primary care system.

\section{Limitations}

This study has some limitations. First, this is a crosssectional study and it is not possible to determine causality of the findings. Second, since it is a practitioner's survey, no data were collected from other primary care health professionals. Third, the self-reporting by primary care practitioners may be biased by social desirability whereby the primary care practitioners might over-report their optimistic views on delivery care services. There is also a possibility that the patients' experiences may differ from what the primary care practitioners have reported. Another limitation may be the extent to which the practitioners are involved in primary care which may differ between countries with strong and weak primary care. It is possible that standards within the primary care profession differ resulting in variation in how critical primary care practitioners are and in their expectations toward primary care. Nevertheless, we are confident with the findings to certain levels because much of the study findings are supported by many other studies related to primary care services.

\section{CONCLUSIONS}

There is a wide variation in primary care services delivery across and within the studied countries. Generally, the HICs fared better in comprehensiveness, continuity and coordination but poorer in accessibility to services compared with UMICs. England was ranked top position in delivering a comprehensive, coordinated and continued care whereas Malaysia was the best among the UMICs in comprehensiveness and coordination. The findings in this study indicate that those identified service delivery process dimensions can be focused for quality improvement activities to strengthen primary healthcare services of that particular country. Importantly, continuous quality improvement efforts which emphasise on issues such as ageing population, the health inequities, the high prevalence of chronic diseases, workforce shortages and technology change as well as rising healthcare expenditures in response to population health needs are also essential for enhancing primary care strength.

\section{Author affiliations}

${ }^{1}$ Centre for Clinical Outcome Research, Institute for Clinical Research, Shah Alam, Selangor, Malaysia

${ }^{2}$ Family Medicine, Universiti Kebangsaan Malaysia Medical Centre, Kuala Lumpur, Kuala Lumpur, Malaysia

${ }^{3}$ Netherlands Institute for Health Services Research (NIVEL), Utrecht, The Netherlands

${ }^{4}$ Departments of Human Geography and Department of Sociology, Utrecht University, Utrecht, The Netherlands

Acknowledgements We would like to thank the Director General of Health Malaysia for the approval to publish this manuscript. We would also like to acknowledge the contribution and support of Willemijn Schafer, and Wienke Boerma, from Netherlands Institute for Health Services Research (NIVEL) in the planning and conduct of QUALICOPC Malaysia study. We also wish to express gratitude to all primary care clinics' providers and participants who had participated in and contributed their time and information towards the study and the QUALICOPC team members for their various contributions to this project. This study is a subwork package under the Malaysia Health System Research (MHSR) study registered under the National Medical Research Registry (NMRR 15-607-25769). We would like to thank the coordinators of the data collection in each country: $\mathrm{M}$ Akman (Turkey); C Sirdifield, and N Siriwardena (UK); K. Stavric (FYR Macedonia); D. Farcasanu (Romania); T. Dedeu (Spain); W. Boerma, W. Schäfer, D. Kringos, M. Van den Berg, T. Van Loenen (the Netherlands).

Contributors MTL: conceptualisation, methodology, formal analysis, writingoriginal draft, writing-review and editing. SMO: conceptualisation, methodology, formal analysis, visualisation, writing-review and editing. SFT: conceptualisation, methodology, formal analysis, writing-review and editing. PG: conceptualisation, methodology, formal analysis, writing- review and editing, lead partner of European QUALICOPC. SS: conceptualisation, methodology, writing-review and editing, principal investigator, project manager, funding acquisition.

Funding QUALICOPC Malaysia was supported by a grant from Ministry of Health Malaysia under the Malaysian Health System Research Initiative (MHSR). The QUALICOPC (Quality and Costs of Primary Care in Europe) project was cofunded by the European Commission under the Seventh Framework Programme (FP7/20072013) under grant agreement 242141 . Opinions, results and conclusions reported in this manuscript are those of the authors and are independent from the funding source.

\section{Competing interests None declared.}

Patient consent for publication Not required.

Ethics approval This study was approved by the Medical Research and Ethics Committee (MREC), Ministry of Health Malaysia as part of the Malaysia Health System Research (MHSR) with approval number NMRR-15-607-25769. Ethical approval for the QUALICOPC study was acquired in accordance with the legal requirements in each country (see the overview in De Rosis S, Seghieri C. Basic ICT adoption and use by general practitioners: an analysis of primary care systems in 31 European countries. BMC Med Inform Decis Mak 2015, 15:70.)

Provenance and peer review Not commissioned; externally peer reviewed.

Data availability statement Data are available on reasonable request. The deidentified data are available on reasonable request to protect the confidentiality and privacy of the participants. Request can be made to the corresponding author (ORCID ID: 0000-0002-5430-5040) and coauthor Peter Groenewegen (ORCID ID: $0000-0003-2127-8442$ ) for Malaysian and European data, respectively. Approval of request is subject to the data sharing policy of the organisations.

Supplemental material This content has been supplied by the author(s). It has not been vetted by BMJ Publishing Group Limited (BMJ) and may not have been peer-reviewed. Any opinions or recommendations discussed are solely those 
of the author(s) and are not endorsed by BMJ. BMJ disclaims all liability and responsibility arising from any reliance placed on the content. Where the content includes any translated material, BMJ does not warrant the accuracy and reliability of the translations (including but not limited to local regulations, clinical guidelines, terminology, drug names and drug dosages), and is not responsible for any error and/or omissions arising from translation and adaptation or otherwise.

Open access This is an open access article distributed in accordance with the Creative Commons Attribution Non Commercial (CC BY-NC 4.0) license, which permits others to distribute, remix, adapt, build upon this work non-commercially, and license their derivative works on different terms, provided the original work is properly cited, appropriate credit is given, any changes made indicated, and the use is non-commercial. See: http://creativecommons.org/licenses/by-nc/4.0/.

\section{ORCID iDs}

Ming Tsuey Lim http://orcid.org/0000-0001-5275-9236

Su Miin Ong http://orcid.org/0000-0002-5430-5040

Seng Fah Tong http://orcid.org/0000-0002-8725-1536

Peter Groenewegen http://orcid.org/0000-0003-2127-8442

Sheamini Sivasampu http://orcid.org/0000-0003-2314-6048

\section{REFERENCES}

1 Kringos DS, Boerma WGW, Hutchinson A, et al. The breadth of primary care: a systematic literature review of its core dimensions. BMC Health Serv Res 2010;10:65.

2 Donaldson M, Yordy K. Defining primary care. National Academies Press, 1994.

3 Kringos DS, Boerma W, van der Zee J, et al. Europe's strong primary care systems are linked to better population health but also to higher health spending. Health Aff 2013;32:686-94.

4 Starfield B, Shi L, Macinko J. Contribution of primary care to health systems and health. Milbank Q 2005:83:457-502.

5 Kringos D, Boerma W, Bourgueil Y, et al. The strength of primary care in Europe: an international comparative study. Br J Gen Pract 2013;63:e742-50.

6 Starfield B. Is primary care essential? Lancet 1994;344:1129-33.

7 World Health Organization. Draft charter for general practice/family medicine in Europe : report on a WHO meeting, Copenhagen, Denmark 6-7 February 1998, 1998. Available: http://www.euro.who. int/_data/assets/pdf_file/0007/119167/E60714.pdf [Accessed 18 May 2020].

8 Pettigrew LM, De Maeseneer J, Anderson M-IP, et al. Primary health care and the sustainable development goals. The Lancet 2015;386:2119-21.

9 Hone T, Macinko J, Millett C. Revisiting Alma-Ata: what is the role of primary health care in achieving the sustainable development goals? Lancet 2018;392:1461-72.

10 World Health Organisation. Declaration of Alma-Ata International Conference on primary health care, Alma-Ata, USSR, 6-12 September 1978. Geneva: 1978. who., 1978. Available: https://www. who.int/publications/almaata_declaration_en.pdf?ua $=1$ [Accessed 18 May 2020].

11 Sivasampu S, Wahab YF, Ong SM. National medical care statistics (NMCS) 2014. Kuala Lumpur: National Clinical Research Centre, 2016. http://www.crc.gov.my/nhsi/wp-content/uploads/publications/ nmcs2014/NMCS_2014_fullreport.pdf

12 Lim HM, Sivasampu S, Khoo EM, et al. Chasm in primary care provision in a universal health system: findings from a nationally representative survey of health facilities in Malaysia. PLoS One 2017;12:e0172229.

13 Basu S, Andrews J, Kishore S, et al. Comparative performance of private and public healthcare systems in low- and middle-income countries: a systematic review. PLoS Med 2012;9:e1001244.

14 Mimi O, Tong S, Nordin S, et al. A comparison of morbidity patterns in public and private primary care clinics in Malaysia. Malays Fam Physician 2011;6:19-25.

15 Sivasampu S, Noh K, May Chien C. Quality and Costs of Primary Care (QUALICOPC)- Malaysia Phase 1 Report, 2015.

16 Sivasampu S, Mohamad Noh K, Husin M. Quality and costs of primary care (QUALICOPC) - Malaysia 2016 phase II- private clinics, 2016.
17 Schäfer WLA, Boerma WGW, Kringos DS, et al. Measures of quality, costs and equity in primary health care instruments developed to analyse and compare primary care in 35 countries. Qual Prim Care 2013;21:67-79.

18 Schäfer WLA, Boerma WGW, Kringos DS, et al. QUALICOPC, a multi-country study evaluating quality, costs and equity in primary care. BMC Fam Pract 2011;12:115.

19 Schäfer WLA, Boerma WGW, van den Berg MJ, et al. Are people's health care needs better Met when primary care is strong? A synthesis of the results of the QUALICOPC study in 34 countries. Prim Health Care Res Dev 2019;20:e104.

20 The World Bank. World bank country and lending groups, 2019. Available: https://datahelpdesk.worldbank.org/knowledgebase/ articles/906519-world-bank-country-and-lending-groups [Accessed 13 May 2020].

21 Groenewegen PP, Greß S, Schäfer W. General Practitioners' Participation in a Large, Multicountry Combined General PractitionerPatient Survey: Recruitment Procedures and Participation Rate. Int J Family Med 2016;2016:1-9.

22 Leyland AH, Groenewegen PP. Ecometrics: Using MLA to Construct Contextual Variables from Individual Data. In: Leyland $\mathrm{AH}$, Groenewegen PP, eds. Multilevel modelling for public health and health services research: health in context. Cham: Springer International Publishing, 2020: 123-38.

23 Kringos DS, Boerma WGW, van der Zee J, et al. Political, cultural and economic foundations of primary care in Europe. Soc Sci Med 2013;99:9-17.

24 OECD, European Union. Health at a glance: Europe 2016: state of health in the EU cycle. OECD2016.

25 O'Malley AS, Samuel D, Bond AM, et al. After-Hours care and its coordination with primary care in the U.S. J Gen Intern Med 2012;27:1406-15.

26 Douthit N, Kiv S, Dwolatzky T, et al. Exposing some important barriers to health care access in the rural USA. Public Health 2015;129:611-20.

27 Ayanian JZ, Weissman JS, Schneider EC, et al. Unmet health needs of uninsured adults in the United States. JAMA 2000;284:2061-9.

28 Mounier-Jack S, Mayhew SH, Mays N. Integrated care: learning between high-income, and low- and middle-income country health systems. Health Policy Plan 2017;32:iv6-12.

29 Pickin DM, O'Cathain A, Fall M, et al. The impact of a general practice co-operative on accident and emergency services, patient satisfaction and GP satisfaction. Fam Pract 2004;21:180-2.

30 Lowe RA, Localio AR, Schwarz DF, et al. Association between primary care practice characteristics and emergency department use in a Medicaid managed care organization. Med Care 2005;43:792-800.

31 Margolius D, Bodenheimer T. Redesigning after-hours primary care. Ann Intern Med 2011;155:131-2.

32 Mehrotra A, Wang MC, Lave JR, et al. Retail clinics, primary care physicians, and emergency departments: a comparison of patients visits. Health Aff 2008;27:1272-82.

33 Niska R, Bhuiya F, Xu J. National Hospital ambulatory medical care survey: 2007 emergency department summary. Natl Health Stat Report 2010:1-31.

34 Haggerty J, Burge F, Lévesque J-F, et al. Operational definitions of attributes of primary health care: consensus among Canadian experts. Ann Fam Med 2007;5:336-44.

35 Boerma WG, Groenewegen PP, Van der Zee J. General practice in urban and rural Europe: the range of curative services. Soc Sci Med 1998;47:445-53.

36 Coulter A. Shifting the balance from secondary to primary care. BMJ 1995;311:1447-8.

37 Haggerty JL, Reid RJ, Freeman GK, et al. Continuity of care: a multidisciplinary review. BMJ 2003;327:1219-21.

38 van Loenen T, van den Berg MJ, Heinemann S, et al. Trends towards stronger primary care in three Western European countries; 20062012. BMC Fam Pract 2016;17:59.

39 Phillips C. Care coordination for primary care practice. J Am Board Fam Med 2016;29:649-51.

40 Solberg LI. Care coordination: what is it, what are its effects and can it be sustained? Fam Pract 2011;28:469-70.

41 Masseria Cl, Thomson S, Gemmill M. Primary care in Europe: policy brief. The London school of economics and political science, 2009. 